\title{
Seasonal Exacerbation of Asthma Is Frequently Associated with Recurrent Episodes of Acute Urticaria
}

\author{
Zahava Vadasz $^{\mathrm{a}}$ Aharon Kessel $^{\mathrm{a}}$ Alon Y. Hershko $^{\mathrm{b}, \mathrm{c}}$ Marcus Maurer $^{\mathrm{d}}$ \\ Elias Toubi ${ }^{\mathrm{a}}$ \\ aDivision of Allergy and Clinical Immunology, Bnai Zion Medical Center, Technion, Haifa, ${ }^{b}$ Internal Medicine B, \\ Meir Hospital, Kfar Saba, and ' Sourasky Medical School, Tel-Aviv, Israel; ${ }^{d}$ Department of Dermatology and Allergy, \\ Charité - Universitätsmedizin Berlin, Berlin, Germany
}

\section{Key Words}

Urticaria · Asthma · Seasonal allergy

\begin{abstract}
Background: Asthma and urticaria are both partially mediated by an increased release of histamine from highly activated mast cells. They are pathophysiologically different, as mast cell degranulation in these 2 disorders results from different mechanisms. Objective: To assess the incidence of urticaria in patients with asthma, and of asthma in patients with chronic spontaneous urticaria (CSU). Patients and Methods: Over 1 year of follow-up, asthma patients $(n=110)$ were assessed for the incidence and characteristics of urticaria, and a link, if it existed, to seasonal exacerbations and the severity of asthma was traced. We also prospectively assessed CSU patients $(n=95)$ during the same period of time for the incidence of asthma. Healthy individuals $(n=100)$, serving as a control group, were also assessed. Results: Episodes of urticaria occurred in $26 / 110$ asthma patients (23.6\%), but in only $2 / 100$ healthy control subjects $(2 \%)(p<0.0001)$. During the 1-year observation period, episodes of urticaria were significantly more frequent in asthma patients with positive skin-prick test reactions (mainly seasonal pollens), and consequently occurred mostly during seasonal asthma
\end{abstract}

exacerbation, i.e. during acute episodes of urticaria. The incidence of asthma in CSU patients was recorded in $10.5 \%$ of the group, similar to that in the healthy control population. Discussion: Our study demonstrates, for the first time, that asthma patients frequently develop acute urticaria, mainly during seasonal exacerbations. In contrast, CSU patients do not show an increased incidence of asthma.

두 2016 S. Karger AG, Base

\section{Introduction}

Bronchial asthma and urticaria are highly prevalent and disabling mast cell-mediated conditions. They differ in their mast cell-activating triggers, but are similar in that histamine and other inflammatory mast cell mediators are involved in their pathogenesis. Both disorders include the involvement of cytokines/mediators such as IL4, IL10, IL-33 and B cell-activating factor (BAFF) - all of which contribute to the activation of many immune cells and the influx of leukocytes to the dermis and airways [1-3]. In both conditions, IgE is frequently elevated and anti-IgE therapy is highly effective. They also improve in response to glucocorticosteroids, and antihistamines are widely used in their treatment [4-6]. Based on these sim-

\section{KARGER}

E-Mail karger@karger.com

www.karger.com/iaa (c) 2016 S. Karger AG, Basel

$1018-2438 / 16 / 1694-0263 \$ 39.50 / 0$
Correspondence to: Prof. Elias Toubi

Division of Allergy and Clinical Immunology

Bnai Zion Medical Center, Technion

IL-31048 Haifa (Israel)

E-Mail elias.toubi@b-zion.org.il 


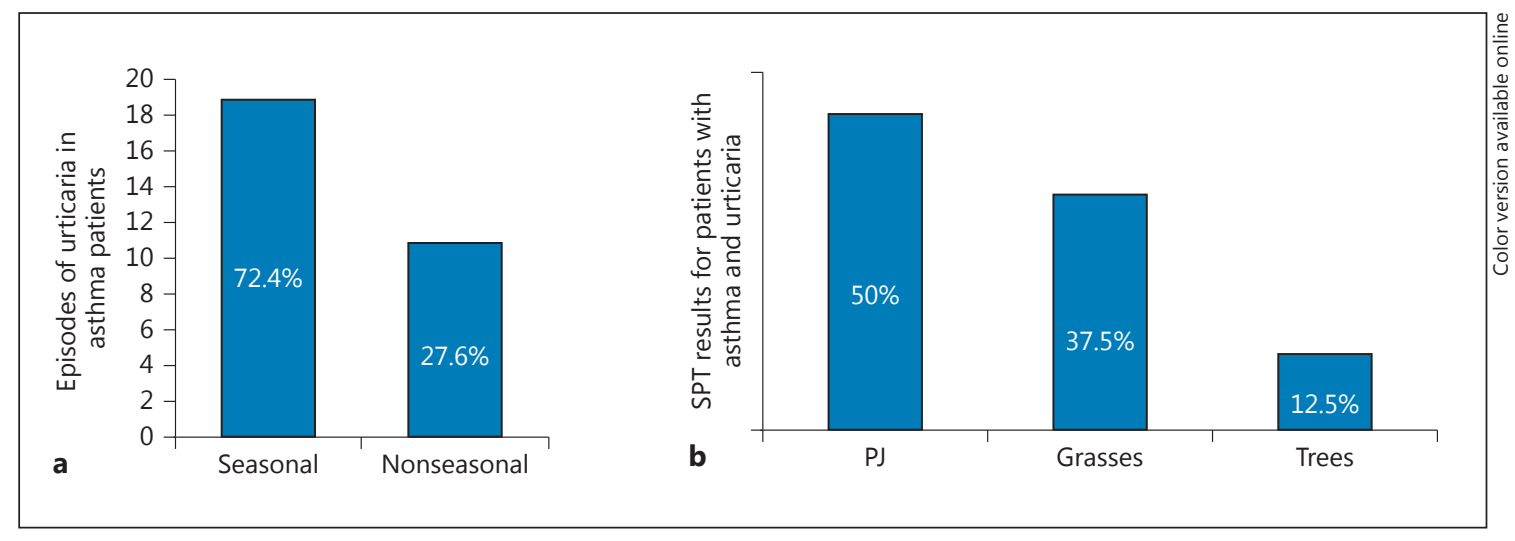

Fig. 1. a Among all asthma patients in whom urticaria was recorded, $72.4 \%$ of the episodes occurred during seasonal exacerbations of asthma. In contrast to this, in $27.6 \%$ of patients, the episodes were nonseasonal $(\mathrm{p}<0.001)$. b Among all asthma patients who developed urticaria, 19 (73\%) were SPT-positive to seasonal aeroallergens. This was especially noticeable in patients with a high sensitivity to PJ.

ilarities, researchers suspect that asthma and urticaria are linked and that they frequently occur in the same patient. Indeed, patients who suffer from severe attacks of urticaria frequently report sensations of 'respiratory distress', although this is mostly not real asthma. Conversely, asthma patients experience itch (of the nose, ears and eyes) but rarely develop wheals. Though mentioned in a few small reports, asthma was shown to be prevalent in patients suffering from chronic spontaneous urticaria (CSU) $[7,8]$. Our group and other researchers have previously reported on total IgE elevations in the serum of CSU patients and found IgE levels to be linked to CU severity. In our study, and in line with the recently published guidelines on CSU, total IgE elevations were not associated with skin test positivity to aeroallergens $[9,10]$. As of now, no conclusive studies have clarified whether urticaria is more prevalent in patients suffering from asthma. This report is the first that is based on a large-scale study examining the occurrence of asthma in CSU patients and of urticaria in asthma patients.

\section{Patients and Methods}

The study included patients with asthma $(\mathrm{n}=110)$, patients with CSU $(n=95)$ and healthy controls $(n=100)$. Both groups of patients were under the follow-up of our Outpatient Allergy Clinic at Bnai Zion Medical Center, Haifa, Israel. All patients (CSU and asthma) were assessed over the course of 1 year via questionnaires. Asthma patients were asked about their respiratory complaints, seasonality and severity according to the current GINA classification [11]. All asthma patients underwent skin-prick tests (SPT) for aeroallergens, i.e. mites, grasses, trees and Parietaria judaica (PJ) weeds, and at least 2 spirometry tests on 2 occasions. They were asked if they suffer from recurrent attacks of urticaria (seasonal?), about the number of attacks per year and also their duration. Of importance is to note that our patients were familiar with the symptoms of urticaria and were able to differentiate urticaria from other skin symptoms.

The frequency of asthma in CSU patients was determined by means of a questionnaire. The severity of urticaria was assessed using the validated Urticaria Activity Score (UAS7) [12], performed close to every visit. Questionnaire results were analyzed for the correlation of clinical features and rates of comorbidity in both groups of patients. All patients signed an informed consent and the study was approved by the local Helsinki committee at the Bnai Zion Medical Center.

\section{Results}

Asthma Patients Frequently Have Urticarial Episodes

During the 1-year observation period, 26 of the 110 asthma patients (23.6\%) and only 2 of the 100 healthy control subjects (2\%) reported episodes of urticaria $(\mathrm{p}<$ $0.0001)$. Urticarial episodes in asthma patients were similar to those classically observed in patients with CSU: itchy and transient wheals and flare-type skin reactions that occur in the absence of any specific triggers such as drugs. None of the patients exhibited angioedema. In 18 of the 26 asthma patients in whom urticaria developed, this occurred during the exacerbation of asthma in Spring (fig. 1a). Episodes of urticaria were few (mean number of episodes/year: $2.9 \pm 0.8$ ) and short, lasting 2-5 days each (mean $3.5 \pm 1.05$ days). In most cases, urticaria was mild 
and responded well to antihistamine treatment. In 4 patients, episodes persisted for several months, with recurrence after a short remission. In 3 patients, urticaria was severe, antihistamine-resistant $(\mathrm{UAS} 7=32)$ and required the use of omalizumab.

The Incidence of Urticarial Episodes in Asthma

Patients Is Linked to Allergic Sensitization

Among all asthma patients in whom urticarial episodes occurred, 19 (73\%) showed SPT positivity to common, regionally relevant pollens, i.e. grasses, PJ and trees. Urticarial episodes were especially frequent in asthma patients who showed a strong sensitization to PJ (fig. 1b). In 7 patients, episodes of urticaria occurred outside of the pollen season. Five of these patients were SPT-positive to mites and only 2 did not demonstrate positive SPT reactions. Most asthma patients who developed urticaria had a GINA score of 3 or 4 (mean $3.4 \pm 1.1$ ). In contrast, asthma patients who remained free of urticaria through the whole observation period had a GINA score of 1 or 2 (mean 1.4 \pm 0.8 ), highlighting the fact that the asthma of patients who developed urticaria was markedly more severe.

\section{Patients with Chronic Spontaneous Urticaria Do Not} Show Increased Rates of Asthma

Sixty-four of the 95 CSU patients studied had a UAS7 of $22-36$ points (mean $28 \pm 2.3$ ) and were thus considered to have a moderate-to-severe form of the disease. The remaining 31 had UAS7 scores of 10-16 (mean $14 \pm 1.2$ ), i.e. mild-to-moderate disease activity. The above UAS7 scores were the mean score of all visits during the study period. Ten of the $95 \mathrm{CSU}$ (10.5\%) patients reported incidents of asthma during the 1-year study period, similar to the incidence recorded in our healthy control population (9/100 patients, i.e. $9 \%)$. Of these 10 patients, 2 had a history of previous asthma. In the other 8 , asthma first appeared during the observation period. Asthma was mild-to-moderate (GINA 1 or 2) and responded well to inhaled steroids.

\section{Discussion}

This study shows that the incidence of acute but not chronic urticaria is increased in asthma patients. In contrast, the incidence of asthma in CSU is not increased. Inflammation in bronchial asthma involves the upper and lower airways but rarely any other organs. CSU presents mainly with skin symptoms, considered to be secondary to local vascular leak, whereas airway symptoms

Incidence of Urticaria in Asthma Patients are not a key feature and are in fact rare in patients with CSU. In asthma, airway-inflammatory cell infiltrates include eosinophils, lymphocytes, plasma cells and mast cells. When histamine and tryptase values are assayed in nasal fluids, increased levels are found and high levels are associated with severe rhinitis, nasal polyposis and asthma [13]. Asthma exacerbation has been shown to occur in association with the increased secretion of IL-33, an important regulator in allergic disorders. IL-33 activates several immune cells, including mast cells and basophils, in the airways and skin. This may explain why asthma is connected in some cases with the development of acute urticaria $[14,15]$.

\section{IgE in Asthma and CSU}

Most asthma patients, in particular those with seasonal exacerbations, have high titers of specific IgE to mites, grasses and PJ, which saturates most mast cells in the airways, but also in the skin. As mentioned above, increased total serum IgE was also reported in the CSU patients, in association with urticarial disease severity. In these cases, the IgE was shown to be polyclonal and of no specificity to any aeroallergen. Increased IgE is usually associated with increased FcERI expression on mast cells and their increased degranulation and the secretion of inflammatory cytokines. This association could explain why, in severe asthma, peripheral mast cells may also undergo degranulation during exposure to the relevant allergens [16]. Serum levels of eosinophilic cationic protein (ECP) and eosinophilic protein $\mathrm{X}$ are reportedly elevated in asthma patients, mainly in those sensitized to pollens such as grasses. Both ECP and eosinophilic protein X levels were significantly higher when asthma was worse and more therapy was needed. In this respect, increased ECP was found to exist in association with increased specific IgE to seasonal pollens $[17,18]$. The above may increase the expression of vascular endothelial growth factor (VEGF), 1 of the major mediators of vascular permeability in urticaria, and thereby connect asthma with acute episodes of urticaria. This may explain how elevated IgE and ECP serum levels could possibly contribute to the degranulation of skin mast cells [19].

\section{SPTs in Asthma and CSU}

In our study, episodes of urticaria occurred mostly in asthma patients in association with SPT positivity to aeroallergens. One may, therefore, speculate that the urticaria was related to the high level of specific IgE secreted as a reaction to these pollens, leading to intense peripheral skin mast cell degranulation and the episodes of acute 
urticaria. The association between urticaria and the intense exposure to PJ, olive trees and grasses led to the assumption that the urticaria could have had a contact character. Our study took place in a region where PJ is one of the main, long-lasting pollens. Direct contact with these weeds was reported (personal experience) to cause severe urticaria and, in many cases, even severe systemic symptoms, emphasizing the issue of contact urticaria. However, we would like to speculate that, even when not in direct contact, close proximity to PJ or olive trees cause what could be defined as 'contact-like urticaria'. In this case, contact with protein of low molecular-weight (aller- gens/haptens), such as that of PJ, is essential and could be the cause of immunological (IgE-mediated) contact urticaria. This speculation should remain a subject for further study.

Further studies are required to establish, more conclusively, the occurrence of episodes of urticaria in patients suffering from moderate-to-severe bronchial asthma, mainly those who experience seasonal exacerbation. In addition, once this has been established, we need to understand more fully the mechanism of pollen-induced skin mast cell degranulation and the reason why airway mast cells are not involved even when CSU is severe.

\section{References}

1 Papadopoulos J, Karpouzis A, Tentes J, Kouskoukis C: Assessment of interleukins IL4, IL-6. IL-8, IL-10 in acute urticaria. J Clin Med Res 2014;6:133-137.

2 Saluja R, Khan M, Church M, Maurer M: The role of IL-33 and mast cells in allergy and inflammation. Clin Transl Allergy 2015;5:33.

3 Kessel A, Yaacoby-Bianu K, Vadasz Z, Peri R, Halasz K, Toubi E: Elevated serum B-cell activating factor in patients with chronic urticaria. Hum Immunol 2012;73:620-622.

4 Toubi E, Kessel A, Avshovich N, Bamberger E, Sabo E, Nusem D, Panasoff J: Clinical and laboratory parameters in predicting chronic urticaria: a prospective study of 139 patients. Allergy 2004;59:869-873.

5 Ferrer M, Sastre J, Jauregui I, Davila I, Montoro J, del Cuvillo A, Mullol J, et al: Effects of anti-histamine up-dosing in chronic urticaria. J Investing Allergol Clin Immunol 2011;3: 34-39.

6 Mizuma H, Tanaka A, Uchida Y, Fujiwara A, Manabe R, Furukawa H, Kuwahara N, et al: Influence of omalizumab on allergen-specific IgE in patients with adult asthma. Int Arch Allergy Immunol 2015;168:165-172.

7 Asero R, Madonini E: Bronchial hyperresponsiveness is a common feature in patients with chronic urticaria. J Investig Allergol Clin Immunol 2006;16:19-23.

8 Isik AR, Karakaya G, Celikel S, Demir AU, Kalyoncu AF, Association between asthma, rhinitis, and NSAID hypersensitivity in chronic urticaria patients and prevalence rates. Int Arch Allergy Immunol 2009;150: 299-306.

9 Kessel A, Helou W, Bamberger E, Sabo E, Nusem D, Panassof J, Toubi E: Elevated serum total IgE - a potential marker for severe chronic urticaria. Int Arch Allergy Immunol 2010;153:288-293.

10 Zuberbier T, Aberer W, Asero R, BindslevJensen C, Brzoza Z, Canonica GW, Church MK, et al: The EAACI/GA(2) LEN/EDF/ WAO Guideline for the definition, classification, diagnosis, and management of urticaria: the 2013 revision and update. Allergy 2014; 69:868-887.

11 Lim SY, Jo YJ, Chun EM: The correlation between bronchial hypersensitiveness to methacholine, and asthma like symptoms by GINA questionnaires for the diagnosis of asthma. BMC Pulm Med 2014;14:161-165.

12 Weller K, Maurer M, Grattan C, Nakonechna A, Abuzakouk M, Berard F, Sussman G, et al. ASSURE-CSU: a real-world study of burden of disease in patients with symptoms of CSU. Clin Transl Allergy 2015;5:29-32.

13 Groger M, Klemens C, Wendt S, Becker S, Canis M, Havel M, et al: Mediators and cytokines in persistent allergic rhinitis and non-allergic rhinitis with eosinophilia syndrome. Int Arch Allergy Immunol 2012;159:171-178.

14 Bahrami Mahneh S, Movahedi M, Aryan Z, Bahar MA, Rezaei A, Sadr M, Rezaei N: Serum IL-33 is elevated in children with asthma and is associated with disease severity. Int Arch Allergy Immunol 2015;168:193-196.
15 Kay AB, Clark P, Maurer M, Ying S: Elevations in T-helper-2-initiating cytokines (IL33 , IL-25 and thymic stromal lymphopoitin) in lesional skin from chronic spontaneous urticaria. Br J Dermatol 2015;172:12941302.

16 Hong GU, Park BS, Park JW, Kim SY, Ro JY: IgE production in CD40/CD40L cross-talk of $\mathrm{B}$ and mast cells, and mediator release via TGase in mouse allergic asthma. Cell Signal 2013;25:1514-1525.

17 Jonsson UB, Hakansson LD, Jogi R, Janson C, Venge P: Associations of ECP (eosinophil cationic protein)-gene polymorphisms to allergy, asthma, smoke habits and lung function in two Estonian and Swedish sub cohorts of the ECRHS II study. BMC Pulm Med 2010;10: 36-44.

18 Acharya KR, Ackerman SJ: Eosinophil granule proteins: form and function. J Biol Chem 2014;289:17406-17414.

19 Kay AB, Ying S, Ardelean E, Mlynek A, Kita $\mathrm{H}$, Clark P, Maurer M: Calcitonin gene-related peptide and vascular endothelial growth factor are expressed in lesional but not uninvolved skin in chronic spontaneous urticaria. Clin Exp Allergy 2014;44:1053-1060.

20 Barbaud A, Poreaux C, Penven E, Waton J: Occupational protein contact dermatitis. Eur J Dermatol 2015;25:527-534.

21 Asero R: Peach-induced contact urticaria is associated with lipid transfer protein sensitization. Int Arch Allergy Immunol 2011;154: 345-348. 